\title{
Notiz über das Molekulargewicht des Quecksilberjodids.
}

\author{
Von
}

W. Herz und M. KNoce.

Gelegentlich der von uns ausgeführten Löslichkeitsbestimmungen des Quecksilberjodids in Alkohol-Wassergemengen ${ }^{1}$ haben wir sein Molekulargewicht in alkoholischer Lösung nach der Methode der Siedepunktserhöhung bestimmt.

In $22.633 \mathrm{~g}$ absoluten Alkohols wurden $0.4171 \mathrm{~g}$ Quecksilberjodid gelöst. Die Siedepunktserhöhung im üblichen Bғскмansschen Apparate betrug $0.052^{\circ}$. Setzen wir in der bekannten Gleichung

$$
M=k \frac{p}{\Delta}
$$

$k$ die molekulare Siedepunktserhöhung des Alkohols nach BЕскмамN ${ }^{2}$ gleich 12.085 , so wird

$$
M=428
$$

Da der theoretische Wert für $\mathrm{Hg}_{2} \mathrm{~J}_{2} 453.9$ beträgt, ist also das Salz in alkoholischer Lösung undissoziiert und monomolekular. ${ }^{3}$

'Z. anury. Chem. 45, 265.

${ }^{2}$ Zeitschr. phys. Chem. 18, 501.

"Siehe hierzu J. Schnoedrr, Z. anorg. Chem. 44, 16.

Breslau, Chem. Institut der Universität, 22. Jnni 1905.

Bei der Redaktion eingegangen am 23. Juni 1905. 